\title{
Memória, Duração e Pulsão em Tarkovsky e Soderbergh: Em Torno do Filme Solaris
}

\author{
Eliza Bachega Casadei \\ Doutoranda em Ciências da \\ Comunicação pela Escola de \\ Comunicações e Artes da Universidade \\ de São Paulo (ECA/USP) e Professora \\ dos Cursos de Comunicação Social do \\ Complexo Educacional FMU-FIAM- \\ FAAM.
}

Resumo: A memória funciona como ponto nodal das narrativas dos filmes Solaris dirigidos por Tarkovsky (1972) e Soderbergh (2002). Tratam-se, no entanto, de duas memórias diferentes que estão implícitas nos elementos fílmicos das duas obras. O presente artigo busca estudar os elementos que nos permitem perceber a diferença, bem como a maneira a partir da qual ela se articula. Se Tarkovsky se aproxima de uma visão bergsoniana da memória, Soderbergh a articula enquanto montagem de pulsões, revelando, assim, a extensão que a mudança na percepção pessoal de um objeto pode trazer para a obra cinematográfica.

Palavras-Chave: memória; Solaris; Tarkovsky; Soderbergh.

Abstract: Memory works as a nodal point in the narratives of both Solaris directed by Tarkovsky (1972) and Soderbergh (2002). These are, however, two different memories that are implicit in the film elements of the two works. This article aims to study the elements that allow us to perceive its differences and the way that it is articulated. While Tarkovsky is closer to a Bergsonian vision of memory, Soderbergh articulates it as a mounting of pulsions, revealing the extension of change that the self perception of an object can bring to the cinematographic work.

Keywords: memory; Solaris; Tarkovsky; Soderbergh.

Em seu livro Esculpir o Tempo, Tarkovsky (2002) chama a atenção para o fato de que "em si mesmos, os fatos registrados naturalisticamente são absolutamente inadequados para a criação da imagem cinematográfica. No cinema, a imagem baseia-se na capacidade de apresentar como uma observação a percepção pessoal de um objeto". A extensão que a mudança nesta "percepção pessoal de um objeto" pode trazer para a obra cinematográfica pode ser percebida quando analisamos o seu filme Solaris (1972), comparando-o com o homônimo de Soderbergh, de 2002.

Os dois filmes contam a estória do livro homônimo de Stanisław Lem: o psicólogo Chris Kelvin é chamado para uma missão em uma nave espacial que orbitava o planeta Solaris, cujos membros estavam apresentando sinais de desgaste físico e emocional. Em um determinado ponto, o próprio Chris começa a duvidar de sua sanidade, na medida em que ele se depara com a materialização de sua esposa morta, que havia se suicidado anos antes.

Embora a questão da memória funcione como ponto nodal nos dois enredos, não obstante isso, podemos observar que se tratam de dois conceitos muito diferentes de memória que estão implicados a partir do trabalho com os 
elementos narrativos e imagéticos nos dois filmes, tratam-se de duas percepções absolutamente distintas em torno do mesmo objeto. $O$ objetivo do presente artigo é estudar quais são esses elementos fílmicos que nos permitem perceber essa diferença, bem como a maneira a partir da qual ela se articula. $E$, assim, enquanto a versão de Tarkovsky se aproxima de uma visão bergsoniana da memória, a de Soderbergh se articula em torno de uma concepção mais próxima da memória entendida enquanto montagem de pulsões e, portanto, mais psicanalítica.

\section{A Memória de Tarkovsky e de Bergon: Percepção e Duração}

Embora a memória não pareça ser o tema central no livro de Tarkovsky em um primeiro vislumbre, podemos perceber a centralidade deste conceito na obra a partir da homologia que o diretor faz entre a noção de tempo e a noção de memória. Para ele, a memória "é algo tão complexo que nenhuma relação de todos os seus atributos seria capaz de definir a totalidade das impressões através das quais ela nos afeta. A memória é um conceito espiritual!" (TARKOVSKY, 2002: 64), de forma que tempo e memória são entendidos por ele como sinônimos, uma mesma entidade, inseparáveis como se fossem os dois lados de uma moeda.

"Privado da memória, o homem torna-se prisioneiro de uma existência ilusória; ao ficar à margem do tempo, ele é incapaz de compreender os elos que o ligam ao mundo exterior - em outras palavras, vê-se condenado à loucura" (TARKOVSKY, 2002: 65).

A sua ideia de memória, no entanto, se desvincula da noção de que o passado é apenas aquilo que já está encerrado, na medida em que este é portador de tudo que é constante na realidade do presente. Cada momento do presente vem carregado pelo passado que lhe serve como uma base, de forma que "o tempo não pode desaparecer sem deixar vestígios, pois é uma categoria espiritual e subjetiva, e o tempo por nós vivido fixa-se em nossa alma como uma experiência situada no interior do tempo" (TARKOVSKY, 2002: 66).

Se o passado é a causa e o futuro seu efeito, o autor enfatiza que, não importando o efeito surgido, nós remontamos constante às suas fontes e às suas causas, fazendo o tempo retroceder através da consciência, muito embora uma das características da memória seja justamente o fato de que ela costuma ser destruída pela confrontação com aquilo que lhe deu origem. "Existe, afinal, uma enorme diferença entre a maneira como nos lembramos da casa onde nascemos e que não vemos há muitos anos, e a visão concreta que se tem da casa depois de uma prolongada ausência" (TARKOVSKY, 2002: 30).

E é justamente aqui que ele situa a função do cinema: ao dominar o tempo, os filmes não podem ser senão amplos edifícios de memórias.

Afinal, ao refletir sobre as possibilidades de recriação da vida no cinema, Tarkovsky coloca que os acontecimentos do dia se fixam na memória das pessoas "como algo amorfo, vago, sem nenhuma estrutura ou organização. Como uma nuvem". Apenas os acontecimentos centrais do dia ganham destaque e, portanto, se fixam "como um relato pormenorizado, lúcido no seu significado e claramente definido. Em contraste com o restante do dia, esse acontecimento aparece como uma árvore em meio à cerração" (TARKOVSKY, 2002: 21). Mesmo que determinados objetos do dia possam ter nos causado impulsos anteriores ou associações, muitos deles aparecem incompletos, fortuitos. A questão que se impõe por esse fato é, para Tarkovsky, como transformar essas impressões da vida em material cinematográfico.

E a resposta a essa questão, para o cineasta, é inequívoca: "para ser fiel à vida e intrinsecamente verdadeira, uma obra deve, a meu ver, ser ao mesmo tempo 
um relato exato e efetivo de uma verdadeira comunicação de sentimentos" (TARKOVSKY, 2002: 22).

Isso significa, de uma maneira geral, construir a mise em scéne não de forma a imitar com precisão mecânica os eventos que aconteceram, mas sim, levar em conta os fatores psicológicos que fazem com que um olhar, um gesto ou um acontecimento banal possam ter uma influência brutal sobre um indivíduo.

A noção de memória exposta por Tarkovsky em seu livro dialoga, em muitos pontos, com a noção de memória articulada por Henri Bergson, de forma que essa filiação se mostra nos elementos fílmicos comumente trabalhados por este diretor.

Para Nora (1996), o grande número de resgates da memória que emergem dos diversos grupos e instituições sociais (associações profissionais, grupos minoritários, empresas etc.) mostra que, paradoxalmente, a historicização do passado colocou as pessoas diante de um imperativo de memória que ordena a todo o momento com a força de um mandamento: "lembre-se" ("Thou shalt remember").

Essa emergência do "lembre-se" foi, de certa forma, coincidente com a constatação da importância da memória para a formação dos indivíduos. Ela se torna uma demanda pessoal na medida em que traz consigo uma força coercitiva que diz respeito à descoberta das raízes ou do pertencimento a algum grupo que possa se tornar uma fonte de identidade. Trata-se de um fenômeno cada vez mais aprofundado na medida em quanto menor a vivência e a partilha das memórias coletivas, maior é o encargo do indivíduo nesta busca.

Este é, portanto, o destino ambivalente da memória coletiva que já se anunciava desde o nascimento do termo. Isso porque, como bem pontua Nora, "no final do século passado [século XIX], quando a sociedade rural entrou em colapso e o antigo equilíbrio social foi rompido, a memória se tornou uma questão central no pensamento filosófico com Bergson, no pensamento psicológico com Freud e na literatura autobiográfica com Proust". Estes seriam os grandes marcos do aprofundamento da passagem da memória vivida para a memória interiorizada: a partir destes autores, começa a ficar mais evidente o processo pelo qual "a memória se torna um assunto privado. Como resultado desta psicologização, o ser agora estabelece uma nova relação com a memória e com o passado" (NORA, 1996: 11).

Os trabalhos de Bergson sobre a memória são uma reação ao trabalho de Théodule Ribot que, em 1881, escreve um livro sobre como as ciências do cérebro são capazes de determinar a localização exata das lembranças. Ao dissociar dois tipos de memória - uma memória hábito e uma memória pura - Bergson defende a ideia de que "rememorar e memorizar são dois fenômenos distintos que não se interpenetram, o que não autoriza a mistura reducionista desses dois domínios" (DOSSE, 2003: 279).

A memória bergsoniana não está em um ponto específico do aparelho cerebral, e sim, é posta em relação direta com a sua noção de percepção articulada ao seu conceito de duração, que se refere a um tempo que é vivido e subsiste, ou seja, trata-se de "um devir, mas de um devir que dura, de uma mudança que é a própria substância". E, "assim definida, a duração não é somente a experiência vivida; é também experiência ampliada, e mesmo ultrapassada" (DELEUZE, 1994: 27). Há, portanto, uma identidade entre a memória e a duração na medida em que "por mais breve que uma percepção possa ser, ela sempre ocupa certa duração e envolve, consequentemente, um esforço de memória que prolonga um no outro uma pluralidade de momentos" (BERGSON, 1929: 25). 
Desta forma, para Bergson, o presente e o passado não podem ser tomados como dois momentos distintos, mas sim, como dois elementos que coexistem: como um presente que não para de passar e como um passado que não para de ser. A percepção da memória funciona a partir de um movimento em que o indivíduo dá um salto em direção ao elemento ontológico do passado (o passado em geral) - e, neste sentido, "o passado é uma ontologia pura, a lembrança pura, que tem significação tão-somente ontológica" (DELEUZE, 1999: 43)-e, em seguida, atualiza a lembrança de forma que esta ganha uma existência psicológica.

Deleuze chama a atenção para o fato de que este primeiro salto para o passado em geral não tem relação alguma com as estruturas psicológicas. "Assim como não percebemos as coisas em nós mesmos, mas ali onde elas estão, só apreendemos o passado ali onde ele está, em si mesmo, não em nós, em nosso presente". E, desta forma, "há, portanto, um 'passado em geral', que não é o passado particular de tal ou qual presente, mas que é como um elemento ontológico, um passado eterno e desde sempre, condição para a passagem de todo presente particular" (DELEUZE, 1999: 43).

Ou, em outros termos, "a invocação da lembrança é este salto pelo qual instalome no virtual, no passado, em certa região do passado, em tal ou qual nível de contração".

Já no que diz respeito a esse segundo movimento da memória relacionado á atualização deste passado ontológico, pode-se dizer que "quando, ao contrário, falamos de revivescência, de evocação da imagem, trata-se de algo totalmente distinto: uma vez que nos tenhamos instalado em determinado nível, no qual jazem as lembranças, então, e somente então, estas tendem a se atualizar". E assim, "sob a invocação do presente, as lembranças já não têm a ineficácia, a impossibilidade que as caracterizavam como lembranças puras; elas se tornam imagens-lembranças, passíveis de serem evocadas" (DELEUZE, 1999: 49).

A consequência deste processo é uma ideia de contemporaneidade entre o presente e o passado de forma que "o passado não só coexiste com o presente que ele foi, mas - como ele conserva em si (ao passo que o presente passa) - é o passado inteiro, integral, é todo o passado que coexiste com cada presente" (DELEUZE, 1999: 46). O movimento bergsoniano, portanto, da memória não atua a partir do presente ao passado (ou da percepção à lembrança). O movimento é inverso: ele parte do passado ao presente, da lembrança à percepção.

Ora, se as homologias teóricas entre Bergson e Tarkovsky parecem bastante claras na medida em que, para ambos, o passado está presente integralmente no presente e obedece a esse movimento que o leva da memória à percepção, é necessário refletirmos de este ponto de vista consegue se materializar enquanto elemento fílmico na obra do diretor.

A leitura delueziana da obra de Tarkovsky parece dar conta desse elo entre o filósofo e o trabalho imagético levado a cabo pelo diretor. E isso porque Deleuze identifica em Tarkovsky o trabalho com a imagem-cristal levada até o seu limite. Partindo justamente da mesma ideia bergsoniana de duração, a imagem cristal é aquela que "dá a ver a operação fundamental do tempo: o tempo se desdobrando a cada instante em presente e passado" (PELBART, 2007: 22).

A representação da memória, no filme de Tarkovsky, é articulada fundamentalmente enquanto imagem-cristal. Não há o recurso a outras formas clássicas de se representar a memória no cinema, como o flashback, por exemplo. Todo o passado é articulado enquanto uma imagem que "faz corresponder a uma imagem atual uma imagem virtual, como um duplo ou reflexo", de forma que, em uma mesma cena, "coexistem a duplicidade entre o presente (imagem atual) e seu passado contemporâneo (imagem virtual)" (PELBART, 2007: 22). 
É neste ponto que podemos encontrar a principal diferença que aloca a memória no filme de Tarkovsky como distinta da pressuposta no filme de Soderbergh. Este não só usa o flashback como o recurso que, por excelência, mostra o passado (sem a articulação de imagens-cristais), como também articula a memória enquanto memória traumática. Voltaremos a este tema adiante, depois da descrição de como a memória parece estar articulada na montagem soderberguiana do livro de Stanisław Lem.

\section{Nas Tramas da Memória de Freud e Soderbergh: Repetição e Pulsão}

Embora Soderbergh nunca tenha escrito nada sobre a sua concepção específica de memória, podemos entrever, através dos elementos fílmicos trabalhados na sua versão de Solaris que a memória implicada ali é bastante diferente da pensada por Tarkovsky. Isso fica claro logo na primeira sequência do filme, onde acompanhamos, após o close em uma janela molhada pela chuva que bate no vidro, Chris sentado e imerso em pensamentos na beirada de sua cama quando, de repente, por sobre essa imagem, uma voz de tênue e sensualmente feminina surge: "I love you so much, Chris. Don't you love me anymore?". Para McFarland (2011: 271) há nesta cena a sugestão de uma dor bastante íntima e dolorosa exatamente por ser íntima. "A voz fantasmagórica está excruciantemente perto embora esperançosamente afastada, refletindo o espelho cruel da memória".

Essa primeira presença se repete incessantemente conforme nos é mostrado o desenrolar do dia de Chris. Quando o personagem entra no trem, ele se lembra de que foi aquele o primeiro lugar onde ele havia se encontrado com a mulher dona da voz. O seu posicionamento indiferente com todos à sua volta e mesmo com os seus pacientes confirma o efeito que esta voz repetitiva Ihe causa.

Ora, é justamente em torno da noção de uma memória que se apresenta como uma ação repetida que está articulada a noção freudiana de memória.

Quando Nora posiciona o trabalho de Freud como um marco da passagem da memória coletiva para a obrigação da memória individual, ele está se referindo ao fato de que, com o trabalho da psicanálise, a memória perde a sua inocência original. Na medida em que concebe que determinadas memórias que se supunham perdidas nunca se esgotam totalmente e podem, mais do que isso, gerar traumas e histerias, o paciente é forçado a um dever de memória como caminho da cura. É por isso que, a partir de Freud, "aquele que esqueceu ou quer esquecer alguma coisa tem de justificar-se e estar preparado para uma pergunta - possivelmente penosa - sobre o motivo por que esqueceu". E isso tanto mais "quanto mais intensamente ele estiver convencido de que seu esquecimento não precisa de nenhuma justificativa, pois ele simplesmente esqueceu algo" (WEINRICH, 2001: 188).

Na teoria freudiana, as percepções são depositadas na memória sob a forma de traços que, armazenados em forma de duplicata a partir de princípios diversos, formam uma extensa rede de memórias ligadas em série. Para Freud, todas as memórias ficam retidas, mesmo que elas não se manifestem. Ele coloca, por exemplo, que "não apenas algo, mas a totalidade do que é essencial na infância foi retido nessas lembranças. Trata-se simplesmente de saber como extraí-lo delas pela análise. Elas representam os anos esquecidos da infância tão adequadamente quanto o conteúdo manifesto de um sonho representa os pensamentos oníricos" (FREUD, 1998: 115). Até mesmo as manifestações do inconsciente seguem esse mesmo mecanismo. Afinal,

nestes processos, acontece com extraordinária frequência ser 'recordado' algo que nunca poderia ter sido 'esquecido', porque nunca foi, em ocasião alguma, notado - nunca foi consciente. Com referência ao curso tomado pelos eventos 
psíquicos, parece não fazer nenhuma diferença se determinada 'vinculação de pensamento' foi consciente e depois esquecida ou se nunca, de modo algum, conseguiu tornar-se consciente (FREUD, 1998: 115).

Neste sentido, alguns desejos inconscientes se associam a estas memórias e podem levar a processos de deslocamentos e recalques, quando associadas a determinados eventos do tempo presente. É assim que os traços de memória, ao longo de determinados intervalos de tempo, sofrem um rearranjo, formando novas relações.

O ato neurótico de um paciente é assim explicado a partir de uma lembrança que ele constantemente reproduz (acting-out), não mais como lembrança, mas sim, como uma ação repetida. Segundo Freud (1998: 116), "podemos dizer que o paciente não recorda coisa alguma do que esqueceu e reprimiu, mas o expressa pela atuação ou atua-o (acts it out). Ele o reproduz não como lembrança, mas como ação; repete-o, sem, naturalmente, saber que o está repetindo". Assim, "enquanto o paciente se acha em tratamento, não pode fugir a esta compulsão à repetição; e, no final, compreendemos que esta é a sua maneira de recordar" (FREUD, 1998: 115-116).

O objetivo da análise, neste contexto, seria uma reelaboração destas memórias traumáticas, de forma que é "um triunfo para o tratamento o fato de poder ocasionar que algo que o paciente deseja descarregar em ação seja utilizado através do trabalho de recordar" (FREUD, 1998: 119).

A volta da memória enquanto uma ação repetida é posta enquanto metáfora cinematográfica diversas vezes ao longo do filme.

Em uma cena bastante expressiva neste sentido, após encontrar a cópia de Rheya, Chris pergunta para o outro tripulante da nave, Snow, "what was that?" e este lhe responde "Do you want her to come back?". É a resposta a essa pergunta que posiciona a função da memória do filme, mostrando-a enquanto um passado que não só se manifesta no presente, mas que se repete e, ao se repetir, forma novas ligações com o atual construindo uma rede. McFarland (2011) chama a atenção para este fato quando coloca que "a pergunta de Snow implica que Solaris pode oferecer apenas uma repetição sem fim" da imagem de Rheya.

Para Freud, o material presente em forma de traços de memória está sujeito, de tempos em tempos, a um rearranjo segundo novas circunstâncias (a uma retranscrição), de forma que, "a análise, como uma experiência de ressignificações, vai permitir diversas interpretações do mesmo evento, ou seja, diversos outros significantes podem ser associados ao evento" (QUINET, 2005: 54).

A cena de Soderbergh é exemplar desta possibilidade de finalização da ação repetida através da cura do paciente, representada por uma rearticulação da rede de memórias traumáticas.

Se a esta noção de memória, somarmos a noção freudiana de sintoma, a resposta de Snow se torna ainda mais provocadora, na medida em que, para Freud, o sintoma representa mesmo uma espécie de gozo no indivíduo, uma vez que ele se articula enquanto a busca por uma saída alternativa de satisfação do sujeito frente ao desafio imposto pela repressão libidinal.

Desta forma, mesmo quando reconhecido pelo indivíduo enquanto um sofrimento, o sintoma representa uma satisfação real. "O sintoma é o lugar paradoxal onde o sujeito, sem que ele o saiba, tem a sua satisfação sexual e, também, o seu sofrimento" enquanto "uma satisfação substituta de uma série de fantasias e de recordações de experiências traumáticas" (DIAS, 2006: 401). 
A repetição da memória e a obtenção do prazer, portanto, se encontram intimamente ligadas, na medida em que o princípio da pulsão de morte desenha justamente esse lugar para o qual o indivíduo sempre retorna, "lugar de sofrimento e desprazer, o qual proporciona uma satisfação paradoxal, para além do princípio do prazer, que faz o sujeito gozar de seu mal-estar, traçando as vias por onde circula". E assim, "a necessidade de repetir a mesma coisa é onde se situa o recurso de tudo aquilo que se manifesta do inconsciente sob a forma de reprodução sintomática" (DIAS, 2006: 402).

A resposta de Snow, portanto, provoca Chris ao reconhecimento de que o retorno de Rheya simboliza este lugar que representa ao mesmo tempo o prazer e o sofrimento enquanto ação repetitiva. $E$, neste sentido, não é por acaso que quando a cópia de Rheya Ihe pergunta como era a sua relação com a mulher original, Chris diz que "all I see is you".

Essa cena é particularmente interessante na medida em que podemos encontrar uma cópia quase exata dela no filme de Tarkovsky que, no entanto, é articulada de modo ligeiramente diferente - diferença esta que marca um corte radical nas duas concepções de memória.

Quando o Cris de Tarkovsky pergunta a Snout o que estava acontecendo e este Ihe responde que tudo indica que o oceano de Solaris havia escaneado o cérebro da tripulação, tirando deles alguma coisa igual a pequenas ilhas de memória, Cris replica: "Voltará?". A resposta de Snout, desta vez, é bastante diferente: "Sim e Não".

A inversão pergunta-resposta não é inocente. Se na primeira cena, de Soderbergh, está implicada uma escolha que aproxima a possibilidade de desaparecimento de Rheya à rearticulação da rede de lembranças ligadas ao trauma e à superação de luto, mesmo que à custa da perda do prazer ligado à pulsão de morte, na cena de Tarkovsky este prazer obtido e esta escolha implicada não estão presentes. Não existindo a questão de trauma de fundo, não há exatamente uma cura pressuposta e nem um prazer a ser obtido.

A resposta de Snout indica que sim, provavelmente a imagem de Hari voltaria na medida em que, para Bergson, o passado, em sua totalidade, nos acompanha em cada instante e se inclina sobre o nosso presente, pressionando a consciência a aceitar elementos que de bom grado ela deixaria de fora, de forma que o passado sempre continua presente em nós. Ao mesmo tempo, Hari não voltaria, ao menos não da mesma forma, pois a memória em Bergson também está sempre sujeita a um processo de devir, de forma que o passado se atualiza no presente. E esta atualização não se dá enquanto ação repetitiva, como em Freud, mas enquanto duração, enquanto aquilo "o que difere de si" (DELEUZE, 1999: 103).

Sob esta ótica, podemos analisar outras questões que marcam diferentes constructos em torno da memória no Solaris de Tarkovsky e de Soderbergh.

A questão do trauma, portanto, é um dos elementos centrais que articulam a questão da memória implicada em cada um dos dois filmes. O suicídio de Rheya, bem como suas causas e a imputação de culpa a Chris, é mostrado de forma muito mais explícita no filme de Soderbergh, ficando apenas sugerida no filme de Tarkovsky. A construção do envolvimento emocional implicado no relacionamento Chris-Rheya (em Soderbergh) e Chris-Hari (em Tarkovsky) é muito diferente nos dois filmes: enquanto no primeiro par, há uma relação de envolvimento afetivo maior por parte de Chris, bem como o escancaramento da significação traumática do suicídio, no segundo par, o reaparecimento de Hari se mostra mais como meramente uma presença com a qual se tem que conviver, do que a partir de um envolvimento afetivo mais marcado. 
Isso fica explícito, por exemplo, na cena em que Hari pergunta a Chris, no filme de Tarkovsky: "você pensava em mim". A resposta de Chris é sugestiva: "Só quando eu estava triste". Com exceção da foto presente na casa de seus pais, a presença de Hari não se mostra importante no filme até o aparecimento de sua cópia. A importância emocional maior atribuída à casa dos pais do que à mulher, inclusive, é escancarada no final do filme quando, após o bem-sucedido suicídio da cópia de Hari, Chris retorna à casa dos pais (em sua versão solariana) e se reconcilia com o patriarca, marcando o desaparecimento total da mulher e o restabelecimento de suas relações com o seu passado mais amplo.

É este passado mais amplo que se mostra como o articulador da narrativa e não necessariamente a presença da mulher ou de seu suicídio. Isso fica claro em diversos momentos como quando, por exemplo, o pai de Chris relembra, logo no começo do filme que "essa casa é muito parecida com a do meu avô. Por isso resolvemos fazer uma réplica. Não gosto de modernismos". O mesmo mecanismo também está implicado na cena em que Hari, logo após a sua aparição, mesmo não conhecendo ainda Snout, faz um comentário que alude ao outro cientista, mostrando que, na verdade, a sua memória e a de Chris se fundem: "Lá vai você sair correndo com o cabelo todo bagunçado como o Snout" - personagem este que o próprio Chris havia acabado de conhecer.

Em ambas as cenas, o passado é articulado enquanto devir, enquanto um passado que se reconstrói justamente porque não deixa de existir enquanto experiência presente, engendrado a uma rede de novas articulações. Não é o trauma que importa, mas sim, como essa nova presença passa a ser articulada tanto ao próprio presente quanto ao passado rearticulado, mostrando a mulher como uma mais figura a se lidar dentro dessa rede de relações e não como a principal causa do processo. Em resumo, é o passado enquanto duração e não enquanto trauma.

A articulação do papel da lembrança de Rheya é muito diferente no filme de Soderbergh, onde a presença da mulher é central desde o primeiro instante e o reencontro marca mesmo todo o sentido do filme, expresso em sua própria tagline: "How far will you go for a second chance?". As cenas que remetem ao suicídio são marcadamente mais dramáticas no filme de Soderbergh, marcando mesmo a culpa que o personagem sente pelo trágico destino da moça. Em uma das cenas, ele tenta mesmo se explicar em um quase pedido de desculpas: "I came back for you. I came back that day. I'm sorry".

No fim do filme de Soderbergh, a reconciliação não se dá com este passado total representado pelo pai, mas sim, com a própria mulher, fonte original do trauma. A cura, encontrada no reconhecimento do próprio prazer da repetição é marcada na fala final quando Chris pergunta: "Am I alive, or dead?". E Rheya responde: "We don't have to think like that any more. We're together now. Everything we've done is forgiven. Everything". É o perdão e a escolha pela repetição que marcam o fim da experiência traumática e dos significados atribuídos.

Não é mais o passado total em rearticulação com o presente, mas sim, a repetição de um momento específico como ponto nodal de junção de todas as significações imputadas.

\section{Recursos Fílmicos: Entre o Flashback e a Imagem-Cristal}

A marcação de dois conceitos distintos de memória nos dois filmes pode ser também aludida a partir do trabalho imagético levado a cabo por cada um dos diretores, especialmente no que concerne aos recursos que cada um deles utiliza para representar imageticamente o passado: enquanto Soderbergh utiliza o flashback para mostrar como era a vida de Chris antes de Solaris e a configuração 
de seu relacionamento com Rheya, o passado de Tarkovsky é articulado, fundamentalmente, a partir de imagens-cristais.

Turim (1989) chama a atenção para o fato de que o flashback tem sido utilizado como técnica cinematográfica desde os primeiros tempos do cinema, mesmo nos filmes mudos, como uma forma de criar suspense, de explicar as motivações dos personagens ou, ainda, para compensar o silêncio da falta de diálogos. Para os filmes impressionistas franceses, o flashback era uma forma de transformar os códigos tradicionais de representação para expressar sentimentos e funções psíquicas dos personagens. Mas, a partir dos anos 1940, passou a ser uma técnica muito utilizada em filmes biográficos como forma de destrinchamento da origem de traumas diversos.

Para Deleuze, o uso do flashback marca, no cinema, o encerramento de uma imagem-lembrança que, embora se configure como uma imagem atual, não se prolonga em movimento, mas sim, encadeia-se com uma imagem virtual e forma com ela um circuito. Uma vez que o flashback se configura enquanto um circuito fechado que vai do presente ao passado, fazendo com que este passado retorne ao presente, esta imagem "deve haurir sua própria necessidade de outra parte, exatamente como as imagens-lembrança devem receber de outra parte a marca interna do passado". E assim, "é preciso que não seja possível contar a história no presente. É preciso, portanto, que alguma coisa justifique ou imponha o flashback, e marque ou autentique a imagem-lembrança" (DELEUZE, 2007: 64). Há, portanto, no flashback, uma percepção indicial entre presente e passado.

Sob esta perspectiva, podemos pensar que o índice que justifica o uso do flashback no filme de Soderbergh é, justamente, a instalação do trauma. É ele que justifica a ida do presente ao passado e de volta e que serve como ponto articulador e nodal da história que está sendo contada.

Já o passado de Tarkovsky não se articula enquanto passado indicial, mas sim, enquanto imagem-cristal, que combina em duplicidade o presente (imagem atual) e o seu passado contemporâneo (em imagem virtual). Enquanto imagem cristal, o passado de Tarkovsky é apresentado imageticamente como uma imagem presente que não se conecta com o presente, mas sim, com a sua imagem virtual, mostrando a coexistência entre presente e passado como a própria duração bergsoniana.

Essa representação fica clara em cenas como quando Chris se depara com o vídeo que seu amigo Gilbarian havia Ihe deixado, ou quando ele assiste, junto com Hari, ao vídeo que seu pai havia gravado (vídeo esse que, por sinal, combina diferentes momentos do passado, perpassando da infância à vida adulta de Chris). A imagem virtual e a atual coexistem, gerando um complexo conjunto de significações que não pode expressar nada senão a própria duração.

Esse trabalho com a imagem do passado dos dois diretores, bem como as consequências disso em termos da representação da memória se confirma também nos tipos de planos escolhidos por cada um deles.

Em Soderbergh, há um uso bastante marcado do plano médio e do plano americano, sugerindo sentidos de aproximação e intimidade entre espectador e câmera, a partir de uma interação entre personagem e público, que se articulam como elementos importantes já que sugerem o desvelamento do próprio trauma. Já uma característica marcante dos filmes de Tarkovsky é, justamente, a utilização do plano-sequência como forma de expressão, plano este entendido pelo diretor como a própria força-motriz da tessitura cinematográfica. Ora, o plano-sequência não é mais do que a própria expressão da duração, a própria expressão de um presente que não pára de passar em correlação com um passado que não deixa de ser. 


\section{Considerações Finais}

Hayden White (1996), ao falar sobre as representações cinematográficas que giram em torno do passado, chama a atenção para o fato de que as novas representações em torno do decorrido diferem crucialmente do gênero literário surgido no século XIX que recebeu a alcunha de "romance histórico". Isto porque estes eram caracterizados, fundamentalmente, por projetarem uma estória de romance "imaginária" em um cenário histórico supostamente "real". Essa interferência mútua entre uma estrutura manifestamente ficcional com a outra supostamente real tinha o efeito de "endossar os eventos imaginários com a concretude da realidade enquanto, ao mesmo tempo, endossava os eventos históricos com a 'aura' mágica peculiar ao romance" (WHITE, 1996: 18).

Este funcionamento que dava aos eventos reais alguns elementos imaginários enquanto endossava os eventos imaginários com uma certa realidade é subvertida nas obras literárias e cinematográficas atuais. Para White, essa subversão está posta na medida em que estas produções midiáticas trabalham com uma indistinção entre o real e o imaginário. "Tudo é apresentado como se eles fossem da mesma ordem ontológica, ambos reais e imaginários - realisticamente imaginário ou imaginariamente real, com o resultado de que as funções referenciais das imagens dos eventos são bastante tênues" (WHITE, 1996: 19).

Este apagamento de fronteiras entre o real e o imaginado nas representações da memória é um tema central tanto no Solaris de Tarkovsky quanto no de Soderbergh. No entanto, ao partirem de conceitos distintos de memória, essa problematização ganha contornos bastante distintos em cada um dos filmes. A memória enquanto pulsão de Soderbergh e a memória enquanto duração de Tarkovsky são elementos chaves para que possamos perceber como a "percepção pessoal de um objeto", tal como exposto por Tarkovsky, pode transformar uma mesma matéria-prima de base em duas obras de arte tão diferentes, desvelando, assim, a própria tessitura do cinema.

\section{Referências Bibliográficas}

BERGSON, Henri. Matter and Memory. London: George Allen, 1929.

DELEUZE, Gilles. Bergsonismo. São Paulo: 34, 1999.

DELEUZE, Gilles. A imagem-tempo. São Paulo: Brasiliense, 2005.

DIAS, Maria das Graças Leite Villela. "O Sintoma: de Freud a Lacan”. Psicologia em Estudo, volume 11, número 02, 2006, p. 399-405.

DOSSE, François. A História. Bauru, São Paulo: EDUSC, 2003.

FREUD, Sigmund. "Recordar, Repetir e Elaborar". In: Edição Eletrônica Brasileira das Obras Psicológicas Completas de Sigmund Freud. Rio de Janeiro: Imago, 1998.

MCFARLAND, Douglas. "The Philosophy of Space and Memory in Solaris". In PALMER, R.B. e SANDERS S.M. (orgs). The Philosophy of Steven Soderbergh. Kentucky: The University Press of Kentucky, 2011.

NORA, Pierre. Realms of Memory: the construction of the French Past. Nova Iorque: Columbia University Press, 1996.

PELBART, Peter Pál. O Tempo não-reconciliado. São Paulo: Perspectiva, 2007. 
QUINET, Antônio. “Que tempo para a análise?". In: A. Quinet. As $4+1$ condições da análise. Rio de Janeiro: Jorge Zahar, 2005.

TARKOVSKY, Andrei. Esculpir o Tempo. São Paulo: Martins, 2002.

TURIM, Maureen. Flashback in Films: memory and history. London: Routledge, 1989.

WEINRICH, Harald. Lete: arte e crítica do esquecimento. Rio de Janeiro: Civilização Brasileira, 2001.

WHITE, Hayden. "The modernist event". In SOBCHACK, Vivian (ed.). The Persistence of History: cinema, television and the modern event. New York: Routledge, 1996.

Filmes

Solaris (dir. Andrei Tarkovsky), Rússia, Mosfilm, 1972, 167 min.

Solaris (dir. Steven Soderbergh), EUA, Twentieth Century Fox Film Corporation, 2002, 99 min. 